\title{
The algorithm for overload syndrome prevention: Osgood-Schlatter's syndrome as an overload syndrome caused by early inclusion of children in sports and excessive physical activity (sports and recreation)
}

Amela Halilbašić1,2* , Amir Kreso', Muhamed Klepić1, Amila Jaganjac², Dijana Avdić

${ }^{1}$ Public Center for Sports Medicine of Canton Sarajevo, Sarajevo, Bosnia and Herzegovina, ${ }^{2}$ Department of physiotherapy, Faculty of Health Studies, University of Sarajevo, Sarajevo, Bosnia and Herzegovina

\begin{abstract}
Introduction: Osgood-Schlatter's syndrome (Osgood-Schlatter disease [OSD]) is caused by an accumulation of repeated microtraumas and is classified as a type of chronic injury called "overload syndrome". It is considered that the root causes of OSD are accelerated growth as well as excessive sports and recreational activity. Currently, more than $50 \%$ of children of school age are involved in sports activities. In this study, 40 external risk factors were analyzed. The aim of this study was to determine external risk factors and to develop an algorithm for the prevention of injuries caused by overload syndrome through a detailed analysis of Osgood-Schlatter's syndrome.
\end{abstract}

Methods: The research has been conducted on 200 patients who were previously diagnosed with OsgoodSchlatter's syndrome. The participants were divided into two groups, each containing 100 patients, first group - aerobic sports (football and basketball) and the second group - anaerobic sports (karate and taekwondo). Personal information, anthropometric measurements, complete medical, and sports history were taken from the patients. A clinical examination was conducted by the researcher himself. This clinical study was prospective, comparative, analytical, and descriptive. The research was conducted in the Public Center for Sports Medicine of Canton Sarajevo. Software used for statistical data analysis was SPSS for Windows (version 20.0, SPSS Inc., Chicago, Illinois, USA) and Microsoft Excel (version 13 of Microsoft Corporation, Redmond, WA, USA).

*Corresponding author: Amela Halilbašić, Public Centre for Sports Medicine of Canton Sarajevo, Patriotske Lige36, Sarajevo, Bosnia and Herzegovina. Tel: +38761503125. E-mail: amela.halilbasic@gmail.com

Submitted: 10 October 2019/Accepted: 30 November 2019

DOI: httbs://doi.ora/10.17532/ihsci.2019.895
Results: Patients experienced the first symptoms of OSD at 4 years (football) and 6 years (taekwondo). About $60 \%$ of patients who trained in anaerobic sports and $38 \%$ of patients who trained in aerobic sports trained other sports more often as well. The research showed that a higher percentage of patients who trained anaerobic sports trained multiple sports at the same time (karate $88 \%$, and taekwondo $82 \%$ ) compared to patients who trained aerobic sports 
(football 68\%, and basketball $76 \%$ ). Patients who trained in anaerobic sports were also more likely to engage in recreational activities (58.3\%) compared to patients who trained in aerobic sports (41.7\%).

Conclusion: The research showed that patients who trained in anaerobic sports more frequently trained more than one sport at the same time and spent more hours doing recreational activities compared to patients who trained in aerobic sports. By analyzing weekly physical activity, it was concluded that the rest is limited. Future research aims to identify risk factors so that children, parents, and trainers can be educated to work on prevention through teamwork.

Key words: Osgood-Schlatter disease; excessive physical activity; the algorithm of prevention for overload syndrome

\section{INTRODUCTION}

Osgood-Schlatter's syndrome (Osgood-Schlatter disease [OSD]) is caused by an accumulation of repeated microtraumas and is classified as a type of chronic injury called "overload syndrome" $(1,2)$. Overload syndromes are not acute injuries followed by inflammation; they are chronic injuries with degenerative changes which impact the damaged tissue. In cases when sportsmen do not respect rest days in their training plan, overload syndrome can develop even with moderate-intensity training over a longer period. On the other hand, it can be caused by high-intensity training of short duration even if recovery time is respected $(3,4)$. Overload reactions can be interpreted as the organism's biological response to repeated mechanical stimuli. If the strain caused by training by its quality and quantity exceeds the organism's threshold of tolerance, it will result in a bio negative reaction of the organism to structural insufficiency (e.g., anesthesia, apophysitis, entezitis, and stress fracture) $(5,6)$. It is considered that the root causes of OSD are accelerated growth as well as excessive sports and recreational activity $(1,3,7)$. In 2008, the National Council of Sports Medicine announced the results of the latest research, which showed that around 60 million children, age 6-18 years, participated in some form of organized sporting activity. At the same time, about 44 million of them were simultaneously involved in more than one form of sporting activity (8). Currently, more than $50 \%$ of children of school age are involved in sports activities (1). While very little research is done to identify risk factors which lead to overload syndrome impacting children and adolescents, most common factors are often said to be mistakes in the training process, use of improper technique, intensive and frequent training, trainings and competitions that last an entire calendar year, frequent travel, and not enough rest days $(9,10)$. Being aware of the risk factors represents the cornerstone of acting preventively $(2,11,12)$. No previous studies have been found which offer a parallel analysis of aerobic and anaerobic sports as well as contact and non-contact sports. In this study, 40 external risk factors were analyzed. The risk factors were divided into six groups: Risk factors related to sport (26 factors), risk factors related to sports injuries (six factors), risk factors related to sports equipment (two factors), nutrition and liquidity replenishment as risk factors (three factors), and risk factors related to the sports environment (two factors). The pressure that parents and coaches put on children is listed as a special risk factor because of its increasing future importance. Information about possible risks of injuries is less accessible or even unknown among young athletes, which indicates that systematic registration of injuries both in sport and recreational activities is required. The OSD etiology is complex, which means more extensive research should be planned in the future. Since survey results showcase a high percentage of children and parents who are not familiar with overload symptoms, the results of this research should be used in practice by sportsmen, trainers, and parents. Since injuries caused by OSD are classified as chronic, the direct and indirect costs of their treatment are extremely high. Frequent medical examinations, expensive rehabilitation, time-consuming sports activities, and school obligations result in grave socio-economic and financial consequences. All of these factors potentially lead to an increased incidence of inactive children and an epidemic of obesity which indicates an urgent need to take preventive measures to reduce the frequency of injuries $(4,11,13,14$.). The purpose of this study 
was to determine external risk factors and to develop an algorithm for the prevention of injuries caused by overload syndrome through a detailed analysis of Osgood-Schlatter's syndrome concerning different types of sport (football, basketball, karate, and taekwondo).

\section{METHODS}

The research has been conducted on 200 patients who were previously diagnosed with OsgoodSchlatter's syndrome. The participants were, depending on the type of sport in which they were involved, divided into two groups, each containing 100 patients, first group - aerobic sports (football and basketball) and the second group - anaerobic sports (karate and taekwondo). All patients were clinically examined by the use of the same subjective and objective criteria. Personal information, anthropometric measurements, complete medical, and sports history were taken from the patients. A detailed medical and sports history was taken for each patient to perform a cross-section and summation of the external risk factors that led to the appearance of Osgood-Schlatter's syndrome. The clinical examination of both knees on all patients was conducted by the researcher himself. The study was prospective, clinical, comparative, analytical, and descriptive. The research was conducted in the Public Center for Sports Medicine of Canton Sarajevo. For research purposes, medical records of examinees, sportsmen were used. Software used for statistical data analysis was SPSS for Windows (version 20.0, SPSS Inc., Chicago, Illinois, USA) and Microsoft Excel (version 13 of Microsoft Corporation, Redmond, WA, USA).

\section{RESULTS}

Using the ANOVA test, it was proven that the mean age of caratists was statistically significantly lower than the average age of subjects of other subgroups, $\mathrm{F}=3.511 ; p=0.016$. In subgroups, the oldest was those who trained basketball $(13.38 \pm$ 1.36 years), then taekwondo (13.30 \pm 1.71 years). The smallest average age was experienced by karate subjects (12.40 \pm 1.71 years), then football (12.96 \pm 1.88 years) (Table 1 ).

The average age of occurrence of pain or swelling below the knee for subjects in the aerobic sports group was $11.43 \pm 1.84$ years, while in the group of anaerobic sports, it was $11.82 \pm 2.26$ years. Using the ANOVA test, a statistically significant difference was not found between the examined groups $(p=0.680)$ and subgroups $(p=0.821)$ (Table 2).

Using the ANOVA test, it was found that taekwondo $(4.70 \pm 2.18$ years $)$ were trained for the longest time before the first appearance of pain in the knee, and the least basketball players $(3.42 \pm 2.28$ years $)$ $(p=0.007)$ were statistically significantly trained, and there was no statistically significant difference in the groups $(p=0.235)$ (Table 3$)$.

Using the Chi-square test, it was found that respondents who trained anaerobic sports (60\%), compared to aerobic sports subjects (38\%), were statistically significantly more trained in other sports, Chi-square $=8.458 ; p=0.003$. Respondents who trained football and basketball in 19\% of cases also trained other sports. However, respondents who trained karate in $31 \%$ of cases also trained other sports, and this percentage was $29.0 \%$ in the group of respondents who trained taekwondo,

TABLE 1. The average age of patients

\begin{tabular}{lcccccc}
\hline Sport & $n$ & $\mathrm{X}$ & $\mathrm{SD}$ & $\mathrm{SEM}$ & Minimum & Maximum \\
\hline Football & 50 & 12.96 & 1.88 & 0.26 & 5.00 & 15.00 \\
Basketball & 50 & 13.38 & 1.36 & 0.19 & 11.00 & 16.00 \\
Karate & 50 & 12.40 & 1.71 & 0.24 & 8.00 & 15.00 \\
Taekwondo & 50 & 13.30 & 1.71 & 0.24 & 6.00 & 15.00 \\
$\mathrm{~F}=3.511 ; p=0.016$ & & & & & & \\
Aerobic sports & 100 & 13.17 & 1.65 & 0.16 & 5.00 & 16.00 \\
Anaerobic sports & 100 & 12.85 & 1.76 & 0.17 & 6.00 & 15.00 \\
$\mathrm{~F}=1.751 ; p=0.187$ & & & & & &
\end{tabular}

SEM: Standard error of mean, SD: Standard deviation 
which was a statistically significant difference, Chi-square $=6.539 ; p=0.011$ (Table 4).

Using the Chi-square test, it was proven that subjects training anaerobic sports were more often included in more sports (karate 88\%; and taekwondo $82 \%$ ), compared to aerobic sports subjects (football 68\%; and basketball 76\%) $(p=0.009)$ (Table 5).

Using the Chi-square test, it was found that the subjects in anaerobic sports were statistically more frequent $(58.3 \%)$ in recreational sports, compared to aerobicsports subjects $(41.7 \%)$, Chi-square $=16.810$; $p=0.001$. Subjects who trained football in $18 \%$ of cases also dealt with recreational sports, while in basketball players, this percentage was slightly higher, $23.5 \%$. However, $29.8 \%$ of karatists were involved in recreational sports, and this percentage was in the group of subjects who trained taekwondo $28.5 \%$, which is a statistically significant difference, Chi-square $=16.272 ; p=0.001$ (Table 6).

Of the total number of subjects, $90 \%$ of aerobic sports subjects recreated the same sporting sport, while in the group of anaerobic sports, this number was statistically significantly lower and amounted to $13 \%$, Chi-square $=116.176 ; p=0.001$. Using the Chi-square test, a statistically significant difference was not found on the frequency of recreational activities of the same sport concerning the examined groups, Chi-square $=0.041 ; p=0.839$ (Table 7).

Using the ANOVA test, it was found that respondents who trained basketball as a basic sport, had a statistically longer training duration than those of other sports $(p=0.001)$. Analyzing the ratio of additional sports and recreational sports, a statistically significant difference in the duration of training was not found concerning the subgroups tested $(p=0.522)$. The average total number of hours spent by the respondents during the week, in physical activity, was statistically significantly the highest among basketball players, and it was $17.2 \mathrm{~h}$, and the lowest for footballers, $15.7 \mathrm{~h}(p=0.031)$ (Table 8).

In both examined groups, $36 \%$ of aerobic and $37 \%$ of anaerobic sports subjects respected the planned

TABLE 2. The average age of occurrence of Osgood-Schlatter disease

\begin{tabular}{lcccccc}
\hline Sport & $n$ & $\mathrm{X}$ & $\mathrm{SD}$ & $\mathrm{SEM}$ & Minimum & Maximum \\
\hline Football & 50 & 11.28 & 1.91 & 0.27 & 4.00 & 14.00 \\
Basketball & 50 & 11.58 & 1.77 & 0.25 & 7.00 & 15.00 \\
Karate & 50 & 12.38 & 3.03 & 1.84 & 8.00 & 12.00 \\
Taekwondo & 50 & 11.26 & 1.66 & 0.23 & 6.00 & 14.00 \\
$\mathrm{~F}=0.306 ; p=0.821$ & & & & & & \\
Aerobic & 100 & 11.43 & 1.84 & 0.18 & 4.00 & 15.00 \\
Anaerobic & 100 & 11.82 & 2.26 & 0.92 & 6.00 & 12.00 \\
$\mathrm{~F}=0.170 ; p=0.680$ & & & & & & \\
\hline
\end{tabular}

SEM: Standard error of mean, SD: Standard deviation

TABLE 3. The average length of training at the time of pain in the knee

\begin{tabular}{lcccccc}
\hline Sport & $n$ & $\mathrm{X}$ & $\mathrm{SD}$ & $\mathrm{SEM}$ & Minimum & Maximum \\
\hline Football & 50 & 4.41 & 1.85 & 0.26 & 1.00 & 8.00 \\
Basketball & 50 & 3.42 & 2.28 & 0.32 & 00 & 9.00 \\
Karate & 50 & 3.82 & 1.61 & 0.22 & 1.00 & 7.00 \\
Taekwondo & 50 & 4.70 & 2.18 & 0.30 & 1.00 & 9.00 \\
$\mathrm{~F}=4.141 ; p=0.007$ & & & & & & \\
Aerobic & 100 & 3.91 & 2.12 & 0.21 & 00 & 9.00 \\
Anaerobic & 100 & 4.26 & 1.96 & 0.19 & 1.00 & 9.00 \\
$\mathrm{~F}=1.420 ; p=0.235$ & & & & & &
\end{tabular}


TABLE 4. Frequency of training of additional sports

\begin{tabular}{|c|c|c|c|}
\hline \multirow[t]{2}{*}{ Sport } & \multicolumn{2}{|c|}{ Additional sport } & \multirow[t]{2}{*}{ Total } \\
\hline & Yes & No & \\
\hline \multicolumn{4}{|l|}{ Group } \\
\hline Aerobic $n(\%)$ & $38(38.0)$ & $62(62.0)$ & $100(50.0$ \\
\hline Anaerobic $n(\%)$ & $60(60.0)$ & $40(40.0)$ & $100(50.0$ \\
\hline \multicolumn{4}{|l|}{$X^{2}=8.458 ; p=0.003$} \\
\hline \multicolumn{4}{|l|}{ Subgroups } \\
\hline Football $n(\%)$ & $19(19.0)$ & $31(31.0)$ & $50(25.0)$ \\
\hline Basketball $n(\%)$ & $19(19.0)$ & $31(31.0)$ & $50(25.0)$ \\
\hline Karate $n(\%)$ & $31(31.0)$ & $19(19.0)$ & $50(25.0)$ \\
\hline Taekwondo $n(\%)$ & $29(29.0)$ & $21(21.0)$ & $50(25.0)$ \\
\hline$x^{2}=6.539 ; p=0.011$ & & & \\
\hline
\end{tabular}

TABLE 5. Analysis of relationships: One sport versus more sports

\begin{tabular}{lccc}
\hline Sport & $n$ & $\begin{array}{c}\text { One sports } \\
\text { training (\%) }\end{array}$ & $\begin{array}{c}\text { More sports } \\
\text { training (\%) }\end{array}$ \\
\hline Football & 50 & $16(32)$ & $34(68)$ \\
Basketball & 50 & $12(24)$ & $38(76)$ \\
Karate & 50 & $6(12)$ & $44(88)$ \\
Taekwondo & 50 & $9(18)$ & $41(82)$ \\
$X^{2}=8.417 ; p=0.009$ & & \\
\hline
\end{tabular}

vacations. Subjects from the group of anaerobic sports compared to aerobic sports, statistically significantly more often did not respect the planned daily, weekly, monthly, and seasonal breaks, Chisquare $=9.718 ; p=0.007$ (Table 9).

In the group with aerobic sports, the season had an average duration of 9.6 months, and in the anaerobic group of 10.0 months. Using the ANOVA test, a statistically significant difference in the length of the sports season was not established about the examined groups, $\mathrm{F}=2.432 ; p=0.121$ (Table 10 ).

\section{DISCUSSION}

The first symptoms of OSD children had already with 4 years old (football) and 6 years (taekwondo), and we concluded that the early involvement of children in sport is the dominant external risk factors. Malina, Mostafavifar et al., Halilbašić et al., as well as many others consider that the incidence of overload syndrome has increased due to the early inclusion of children in sports. By analyzing the relationship, one sport in relation to
TABLE 6. Incidence of practicing recreational sports

\begin{tabular}{lccc}
\hline Group & \multicolumn{2}{c}{ Recreational sports } & Total \\
\cline { 2 - 3 } & Yes & No & \\
\hline Aerobic $n(\%)$ & $63(41.7)$ & $37(75.5)$ & $100(50.0)$ \\
Anaerobic $n(\%)$ & $88(58.3)$ & $12(24.5)$ & $100(50.0)$ \\
$X^{2}=16.810 ; p=0.001$ & & & \\
Subgroups & & & \\
$\quad$ Football $n(\%)$ & $28(18.5)$ & $22(44.9)$ & $50(25.0)$ \\
$\quad$ Basketball $n(\%)$ & $35(23.2)$ & $15(30.6)$ & $50(25.0)$ \\
$\quad$ Karate $n(\%)$ & $45(29.8)$ & $5(10.2)$ & $50(25.0)$ \\
$\quad$ Taekwondo $n(\%)$ & $43(28.5)$ & $7(14.3)$ & $50(25.0)$ \\
$X^{2}=16.272 ; p=0.001$ & & & \\
\hline
\end{tabular}

TABLE 7. Analysis of average recreation

\begin{tabular}{lcc}
\hline Average recreation & \multicolumn{2}{c}{ Group } \\
\cline { 2 - 3 } & Aerobic & Anaerobic \\
\hline Are you recreating the same sport that you train? \\
$\quad$ Yes $n(\%)$ & $90(90.0)$ & $13(13.0)$ \\
$\quad$ No $n(\%)$ & $10(10.0)$ & $87(87.0)$ \\
$X^{2}=116.176 ; p=0.001$ & & \\
Frequency & & \\
$\quad$ Every day $n(\%)$ & $20(22.2)$ & $2(15.4)$ \\
2-3 times/week $n(\%)$ & $32(35.6)$ & $7(53.8)$ \\
$\quad$ Just on weekend $n(\%)$ & $38(42.2)$ & $4(30.8)$ \\
$X^{2}=0.041 ; p=0.839$ & & \\
\hline
\end{tabular}

more than one sport, we concluded that subjects of anaerobic sports, concerning aerobic sports, often trained more sports at the same time and had more hours of recreation. Hyman concluded that children often train more different sports at the same time, train in more clubs, which means they did not limit their activity to a particular season. By analyzing weekly physical activity, the average number of hours spent by the subjects in physical activity (basic sports, extra sports, and recreational sports) was $17.2 \mathrm{~h}$, taekwondo $16.8 \mathrm{~h}$, 16.7 karatists, and $15.7 \mathrm{~h}$ footballers, and we concluded that the number of hours which respondents spend during the week in the sport is very large, which means that the rest is limited. A very small percentage of subjects did not have additional sports or recreational activities: About 32\% of footballers, $24 \%$ of basketball players, $12 \%$ of karate players, and $18 \%$ of taekwondo. Ristolainen et al. and Halilbašić et al. consider that recreation 
TABLE 8. The average duration (in hours) that respondents time during the week, in physical activity (basic sports, extra sports, and recreational sports)

\begin{tabular}{lcccccc}
\hline Sport & Basic & Extra & Recreational & Total & Aerobic & Anaerobic \\
\hline Football & 5.71 & 4.65 & 5.36 & 15.73 & 16.47 \\
Basketball & 6.93 & 5.18 & 5.10 & 17.22 & \\
Karate & 5.10 & 5.57 & 6.02 & 16.69 & & 16.75 \\
Taekwondo & 6.16 & 4.96 & 5.72 & 16.84 & & \\
$p$ & 0.001 & 0.522 & 0.524 & 0.031 & 0.048 \\
\hline
\end{tabular}

TABLE 9. Organization of free time and recreation

\begin{tabular}{lccc}
\hline Do you have a planned & \multicolumn{2}{c}{ Group } & Total \\
\cline { 2 - 3 } $\begin{array}{l}\text { daily, weekly, monthly, } \\
\text { and seasonal vacation? }\end{array}$ & Aerobic & Anaerobic & \\
\hline Yes $n(\%)$ & $36(36.0)$ & $37(37.0)$ & $73(36.5)$ \\
Yes. but I don't respect & $25(25.0)$ & $42(42.0)$ & $67(33.5)$ \\
it. $n(\%)$ & & & \\
No $n(\%)$ & $39(39.0)$ & $21(21.0)$ & $60(30.0)$ \\
$X^{2}=9.718 ; p=0.007$ & & & \\
\hline
\end{tabular}

TABLE 10. Duration of the sport season

\begin{tabular}{lcccccc}
\hline Group & $n$ & $\mathrm{X}$ & $\mathrm{SD}$ & $\mathrm{SEM}$ & Minimum & Maximum \\
\hline Aerobic & 100 & 9.69 & 1.82 & 0.18 & 5.00 & 12.00 \\
Anaerobic & 100 & 10.07 & 1.60 & 0.16 & 6.00 & 12.00 \\
$\mathrm{~F}=2.432 ; p=0.121$ & & & & & \\
\hline
\end{tabular}

SEM: Standard error of mean, SD: Standard deviation

additionally shortens the recovery time is carried out without control and expert supervision and is a very important external risk factor. The conclusion of the research of Ristolainen et al. and associates was that a small number of free days was the strongest risk factor in the onset of obsessive-compulsive disorder as an overload syndrome. In both examined groups, only $36 \%$ of aerobic and $37 \%$ of anaerobic respondents respected the planned vacations. In the group of aerobic sports, the average duration lasted 9.6 months, and in the group of anaerobic 10.0 months, while in both groups, there were respondents who trained for 12 months. Hyman came to the conclusion that the training process lasts throughout the year, which is beyond the traditional sports program. The conclusions of the study enabled the development of a prevention algorithm by reducing external risk factors in sports for all types of injuries of the type of overload syndrome. The goal of future research should be the identification of risk factors to educate children, parents, and trainers teamwork on prevention.

\section{Algorithm of the prevention}

- Obligatory clinical examination of a specialist in sports medicine, before being included in the training process, and a pre-season clinical examination.

- Make a functional movement screen.

- Mandatory periodic inspections to detect potential damage in time.

- Children should be allowed to choose the kind of sport themselves, but they should also be allowed to change several sports until they decide what it wants.

- Every child needs to find a "real" sport, in which he will have the greatest chances of success.

- Adjust the type of sport to the age of the child.

\section{Recommendation}

\begin{tabular}{ll}
\hline Age & Form of sports activity \\
\hline Younger then 5 & $\begin{array}{l}\text { Game and fun, but not active training } \\
\text { Age 5-7 }\end{array}$ \\
& $\begin{array}{l}\text { Practice various forms of sports activities, } \\
\text { freely, and without coercion (sports at } \\
\text { school or sports academy) }\end{array}$ \\
Age 6-9 & $\begin{array}{l}\text { Running, swimming, gymnastics } \\
\text { (recreational), or some other sport, but very }\end{array}$ \\
Age 10-12 & $\begin{array}{l}\text { Low level of organized sport } \\
\text { Age 13-14 }\end{array}$ \\
\hline
\end{tabular}

- Do not allow an early sports specialization for any kind of sport.

- Athletes should participate in only one team, especially if they have remarkable results and if they are a member of the team that is traveling frequently.

- Educated trainers who will adjust the quality and quantity of training to the age of children. 
- The youngest categories should be trained by the most experienced and most skilled trainers.

\begin{tabular}{lcccl}
\hline Age & $\begin{array}{c}\text { Frequency } \\
\text { (per week) }\end{array}$ & $\begin{array}{c}\text { Duration } \\
\text { (minutes) }\end{array}$ & $\begin{array}{c}\text { Pre-workout } \\
\text { warming } \\
\text { (minutes) }\end{array}$ & Stretching \\
\hline$<5$ & $1-2$ & $50-60$ & $5-10$ & No \\
$6-9$ & 2 & 60 & $5-10$ & $\begin{array}{l}\text { Dynamic } \\
\text { (avoiding } \\
\text { static stress) } \\
\text { Dynamic and } \\
\text { static } \\
\text { Dynamic and } \\
\text { static }\end{array}$ \\
$10-14$ & 3 & $60-90$ & $5-10$ & $5-10$ \\
$15>$ & 5 & $90-120$ & & \\
\hline
\end{tabular}

- Modify the training process according to the age and possibilities of the child's organism (obligatory warming and stretching before and after training, control of the intensity of training, limited repetition of sport-specific movements, strengthening of physical fitness - aerobic training and strength training to adapt to the age of the child, neuromuscular training). Basic guidelines based on practical experience and conclusions of previous research:

- Aerobic endurance training is recommended for the age group of 8-10 years.

- Anaerobic endurance training can be done with an age group of 12-14 years.

- In the pre-season, conditioning programs are recommended.

- Learning and mastering the correct technique.

- Adhering to the rules of the correct game.

- Frequency control of the performance (recommendation: One contest or a fight weekly).

- Vacation planning (daily, weekly, monthly, and annual).

- Appropriate equipment adapted to the type of sport.

- $\quad$ Required protective equipment.

- Good conditions for playing (terrain adapted to sports, and weather conditions).

- The training pad should be adapted to the type of sport. Avoid hard surfaces (concrete, tartan, and artificial grass) and permanent changes in the substrate.

- Adequate nutrition and fluid replacement, and weight control.

- Forbid the use of unauthorized funds and supplements.
- $\quad$ Provide medical coverage at sporting events.

- Provide education not only for trainers but also for athletes and parents themselves.

- Limit the forcing of children by parents or trainers.

- Long-term planning of the training process, especially when it comes to children and adolescents.

\section{CONCLUSION}

The research showed that patients who trained in anaerobic sports more frequently trained more than one sport at the same time and spent more hours doing recreational activities compared to patients who trained in aerobic sports. By analyzing weekly physical activity, it was concluded that the rest is limited. Future research aims to identify risk factors so that children, parents, and trainers can be educated to work on prevention through teamwork.

\section{REFERENCES}

1. Atanda A Jr., Shah SA, O'Brien K. Osteochondrosis: Common causes of pain in growing bones. Am Fam Physician 2011;83:285-91.

2. de Lucena GL, dos Santos Gomes C, Guerra RO. Prevalence and associated factors of Osgood-Schlatter syndrome in a population-based sample of Brazilian adolescents. Am J Sports Med 2011;39:415-20.

https://doi.org/10.1177/0363546510383835.

3. DiFiori JP, Benjamin HJ, Brenner J, Gregory A, Jayanthi N, Landry GL, et al. Overuse injuries and burnout in youth sports: A position statement from the American Medical Society for Sports Medicine. Clin J Sport Med $2014 ; 24: 3-20$

https://doi.org/10.1097/jsm.0000000000000060.

4. Luke A, Lazaro RM, Bergeron MF, Keyser L, Benjamin H, Brenner J, et al. Sports-related injuries in youth athletes: Is overscheduling a risk factor? Clin J Sport Med 2011;21:307-14.

https://doi.org/10.1097/jsm.0b013e3182218f71.

5. Krahl H. Reakcije opterećanja i preopterećenja na sustavu za kretanje športaša. U: Pećina M, Heimer S, editors. Športska Medicina. United Kingdom: Medicinska Biblioteka Zagreb; 1995. p. 193-8.

6. Ristolainen L, Kettunen JA, Waller B, Heinonen A, Kujala UM. Trainingrelated risk factors in the etiology of overuse injuries in endurance sports. J Sports Med Phys Fitness 2014;54:78-87.

7. Halilbašić A, Avdić D, Kreso A, Begović B, Jaganjac A, Marić M. Importance of clinical examination in diagnostics of Osgood-Schlatter Disease in boys playing soccer or basketball. J Health Sci 2012;2:21-8.

https://doi.org/10.17532/jhsci.2012.59.

8. National Council of Youth Sports. Report on Trends and Participation in Organized Youth Sports 2008. Seagate Lane: National Council of Youth Sports; 2013.

https://doi.org/10.14195/978-989-26-1171-6-1.

9. Malina RM. Early sport specialization: Roots, effectiveness, risks. Curr Sports Med Rep 2010;9:364-71.

https://doi.org/10.1249/jsr.0b013e3181fe3166. 
10. Mostafavifar AM, Best TM, Myer GD. Early sport specialisation, does it lead to long-term problems? Br J Sports Med 2013;47:1060-1.

https://doi.org/10.1136/bjsports-2012-092005.

11. Maffulli N, Longo UG, Spiezia F, Denaro V. Sports injuries in young athletes: Long-term outcome and prevention strategies. Phys Sportsmed 2010;38:29-34.

https://doi.org/10.3810/psm.2010.06.1780.

12. Yamagiwa H. Bone and joint diseases in children. Etiology and pathogenesis of osteochondral lesions in children. Osteochondritis dissecans and osteochondrosis. Clin Calcium 2010;20:849-58.

13. Dvorak J, Junge A, Chomiak J, Graf-Baumann T, Peterson L, Rösch D, et al. Risk factor analysis for injuries in football players. Possibilities for a prevention program. Am J Sports Med 2000;28:S69-74.

https://doi.org/10.1177/28.suppl_5.s-69.

14. Hyman M. The Most Expensive Game in Town: The Rising Cost of Youth Sports and the Toll on Today's Families. Boston, MA: Beacon Press; 2012. 